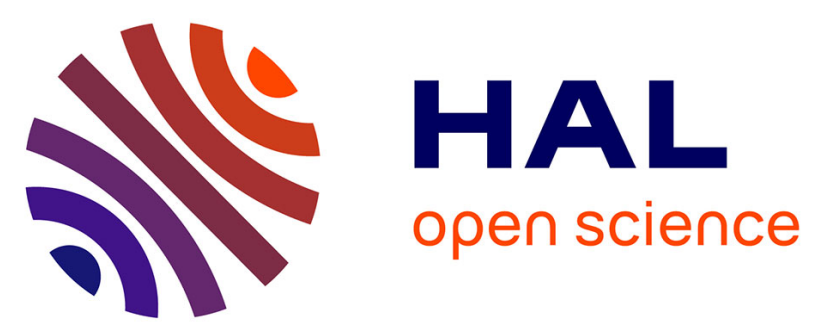

\title{
NIR organic dyes as innovative tools for reprocessing/recycling of plastics: Benefits of the photothermal activation in the near-infrared range
}

Valentin Launay, Aurore Caron, Guillaume Noirbent, Didier Gigmes, Frédéric Dumur, Jacques Lalevée

\section{To cite this version:}

Valentin Launay, Aurore Caron, Guillaume Noirbent, Didier Gigmes, Frédéric Dumur, et al.. NIR organic dyes as innovative tools for reprocessing/recycling of plastics: Benefits of the photothermal activation in the near-infrared range. Advanced Functional Materials, 2021, 31 (7), pp.2006324. 10.1002/adfm.202006324. hal-03144761

\author{
HAL Id: hal-03144761 \\ https://hal.science/hal-03144761
}

Submitted on 17 Feb 2021

HAL is a multi-disciplinary open access archive for the deposit and dissemination of scientific research documents, whether they are published or not. The documents may come from teaching and research institutions in France or abroad, or from public or private research centers.
L'archive ouverte pluridisciplinaire HAL, est destinée au dépôt et à la diffusion de documents scientifiques de niveau recherche, publiés ou non, émanant des établissements d'enseignement et de recherche français ou étrangers, des laboratoires publics ou privés. 


\title{
NIR organic dyes as innovative tools for reprocessing/recycling of plastics: Benefits of the photothermal activation in the near-infrared range
}

\author{
Valentin Launay ${ }^{1,2}$, Aurore Caron ${ }^{1,2}$, Guillaume Noirbent ${ }^{3}$, Didier Gigmes ${ }^{3}$, Frédéric Dumur ${ }^{3}$, \\ Jacques Lalevée*1,2 \\ ${ }^{1}$ Université de Haute-Alsace, CNRS, IS2M UMR 7361, F-68100 Mulhouse, France \\ ${ }^{2}$ Université de Strasbourg, France \\ ${ }^{3}$ Aix Marseille Univ, CNRS, ICR UMR 7273, F-13397 Marseille, France \\ e-mail: jacques.lalevee@uha.fr
}

\begin{abstract}
:
Photoinduced thermal polymerization upon Near-InfraRed (NIR) light has been recently reported in the literature as an efficient tool for polymer synthesis. In these different studies, a component capable to convert a NIR light into heat (called hereafter heater) was used in combination with a thermal initiator, promoting the Free-Radical Polymerization (FRP) of acrylate monomer. In this work, a completely different approach was developed since polymeric materials containing a very low amount of a stimuli-responsive compound were prepared by using a benchmark UV photoinitiator. As the stimuli-responsive compound, an organic dye strongly absorbing in the near infrared region has been selected. The heat released by its irradiation with an inexpensive and highly penetrating (depth in the $\mathrm{cm}$ range) NIR light source allows the development of an unprecedented approach for reprocessing, reshaping, recycling and self-healing. For this purpose, it is important to reach a temperature higher than the glass transition temperature $\left(\mathrm{T}_{\mathrm{g}}\right)$ of the polymeric materials, enabling then to modify their mechanical properties. Several parameters have been studied in order to determine their influence on the polymer temperature: the wavelength of the NIR irradiation, the irradiance of the NIR light source, the choice of heater (IR-813 $p$-toluenesulfonate or a squaraine dye) and the heater concentration. The thermoplastics bonding has also been studied and showed promising results since two pieces of polymers could be pasted together after a short time of NIR irradiation. Reversibility of the bonding was also demonstrated, still while using a NIR light as the activation source. Finally, self-healing ability of the Glyfoma-based thermoplastic was investigated and furnished impressive results even for large scratches. Notably, scratches as deep as $100 \mu \mathrm{m}$ and with a width as large as $500 \mu \mathrm{m}$ could be healed after only a few minutes of NIR irradiation.
\end{abstract}




\section{Introduction}

The use of plastic is widespread and worldwide. In fact, the global plastic production has increased up to more than $4000 \%$ between 1960 to 2013.[1] The low cost and the high versatility of plastics leads us to believe that this global plastic production will continue to grow (or at least stagnate) in the future. Unfortunately, the reprocessing, recycling and recovering of plastics cannot match this huge consumption which engenders high environmental problematics. However, plastic reprocessing or recycling is of crucial interest and the proportion of recycling, recovering and landfilling drastically evolves since 2007. To illustrate this, in $2018,32.5 \%$ of plastics wastes were recycled (against $20.4 \%$ in 2007 ), $42.6 \%$ were recovered (against 29.2\% in 2007) and 24.9\% were landfilled (against 50.4\% in 2007).[2][3] The recycling and recovering of plastics can be separated in four different categories.[4] The first category is the most environmentally friendly and concerns the plastics recycled by reextrusion, also called closed-loop recycling. By using this recycling method, properties of the recycled plastics are quite similar than those of the raw plastic. Therefore, this latter can be replaced by the recycled plastic.[5] For the second category, properties of the recycled plastic are degraded compared to that of the initial materials as mechanical processes are involved in the recycling process. To overcome this drawback, new components can be added such as raw plastics or fillers to restore the mechanical properties. The third category involves chemical processes in which the polymer bonds are cleaved by depolymerization or by the use of high reaction temperatures. As a result of this, products derived from these chemical processes can be employed as feedstock for the fabrication of new plastics or chemicals. Finally, the fourth category called energy recovering consists in incinerating the plastic wastes in order to produce heat or electricity. However, the quantity of $\mathrm{CO}_{2}$ released during this process is a major drawback in the current context of global warming.[6] Thermoplastics constitute around 80\% of the plastic wastes generated throughout the world so that their recycling is the keypoint to avoid the landfilling of plastic wastes.[7]

Self-healing is a good way to improve the lifetime of polymers and to reduce their maintenance costs, notably for the healing of cracks. Various strategies have been developed to reach these self-healing properties but all of them require high temperatures to be reached. For instance, polyurethanes-based polymers showed good self-healing properties upon heating and it is possible to use a small crosslinker presenting hydroxyl groups to improve reversibility of the bond formation or to use the Diels-Alder reaction which provides an excellent thermal 
reversibility.[8][9][10] Fusible thermoplastic polycaprolactone fibers or polystyrene can also be inserted into the matrix. Under the influence of heat, they will melt and flow to heal the scratch.[11][12] Another efficient way to get self-healing properties is to incorporate graphene oxide or nanoparticles into the polymers to produce an efficient photothermal effect which will lead to the melting of the polymer, providing its local deformation upon NIR light irradiation and resulting in healing of the scratch.[13][14][15] It has notably been evidenced that both the nanoparticles concentration and the irradiance could have a dramatic influence on the temperature reached and thus drastically affect healing efficiency.[16] However, nanoparticles agglomerate in the polymer matrix, leading to a loss in mechanical properties and photothermal effect efficiency.[17] All these photothermal effects are based on the use of fillers (multi-walled carbon nanotubes, graphene nanoplatelets, silicon carbide, graphene oxide, etc...) as heaters but they have the strong drawback of being hardly soluble and with low photothermal effect compared to well dissolved organic dyes.[18][19][20] Remarkably, organic dyes (as presented here) are perfectly soluble and stable in the monomers and polymers; this is a huge advantage. In this work, we will be able to reach a very high temperature upon low NIR irradiation intensity and with low heater concentration.

NIR wavelengths are known to enable a greater light penetration into the photocurable resin and to allow a better light-to-heat conversion than the UV-visible wavelengths.[21][22] The mechanisms involved in the production of heat are already well-described in the literature, especially in the medical field through the photothermal therapy.[23][24][25] These wavelengths are also used to initiate crosslinking processes using the heat generation.[26][27] In the present study, the primary goal was to introduce a NIR dye (fully soluble in the polymer contrary to fillers such as graphene oxide or nanoparticles) that could be used, subsequent to the polymerization process, for a light-to-heat conversion enabling the increase of the thermoplastic temperature above its glass transition temperature. Using this strategy, a modification of the thermoplastic's mechanical properties could be achieved and self-healing of the polymer or the possibility to develop a recycling process based on a bonding/debonding strategy done on demand through NIR irradiation could be promoted. This last strategy constitutes an environment-friendly approach to recycle polymers compared to oven heating. Especially, the main advantage of this photochemical approach is to allow an efficient spatial control of the photothermal effect as it is shown on the Scheme 1. More precisely, increase of 
the temperature is only observed in the irradiated areas e.g. for healing or debonding of multimaterials.

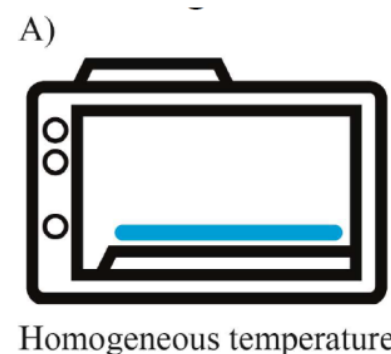

Homogeneous temperature
B)

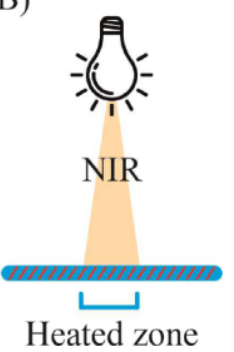

Heated zone

$\begin{array}{ll} & \text { Polymeric material } \\ \text { IIIIIIIIIIIII, Heater }\end{array}$

Scheme 1. Comparison of procedures used for self-healing of polymer surfaces (A) by heating in an oven, the whole surface of the polymer is treated irrespective of the position of the defects (B) the new proposed strategy making use of a NIR laser diode to induce a localized photothermal treatment.

\section{Experimental section}

\subsection{Chemical compounds}

Trimethylolpropane triacrylate (TMPTA) was purchased from Sigma-Aldrich, phenyl bis(2,4,6-trimethylbenzoyl)-phosphine oxide (SPBPO) was obtained from Lambson Ltd (UK), IR-813 p-toluenesulfonate (IR-813) was ordered from Tokyo Chemical Industry (TCI-Europe), crayvallac SLT was provided from Arkema and Glyfoma was supplied from Evonik. The squaraine (SQ) was synthesized according to a procedure recently reported in the literature (the procedure is presented in SI).[28] Chemical structures of the different monomers and additives are presented in the scheme 2 except that of the crayvallac SLT which was used as a thickener.

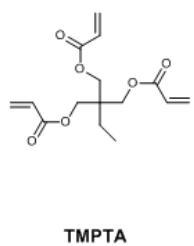

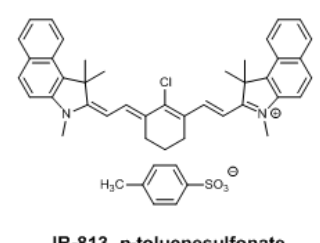

IR-813 p-toluenesulfonate

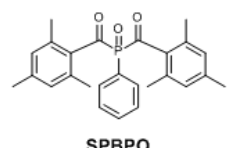

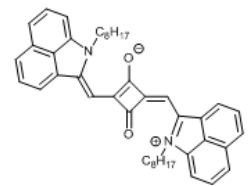

so

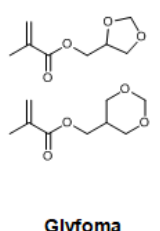

Glyfoma 
Scheme 2. Chemical structures of the monomers (TMPTA, Glyfoma), heaters (IR-813, SQ) and the photoinitiator (SPBPO) used in this study.

\subsection{Polymerization in bulk followed by RT-FTIR spectroscopy}

First, thermoset polymer samples were prepared to test the heater effect for in-situ embedded NIR dyes. In order to prepare this sample, a multifunctional acrylate monomer (TMPTA) was mixed with a UV photoinitiator (SPBPO). In addition, a heater - which is a NIR dye (here, IR-813 or SQ, fully soluble in TMPTA) - was incorporated into the photocurable resin before being polymerized with a laser diode at $405 \mathrm{~nm}$.

Once the heater effect was confirmed, thermoplastic samples were prepared. To get them, a monomer (Glyfoma) was selected as a benchmark monofunctional monomer leading to a thermoplastic polymer. A thickener (crayvallac SLT) was added to control the viscosity of the photocurable sample. Then, the photoinitiator (SPBPO) and the NIR heater (IR-813 or SQ) were both incorporated into the resins.

For the preparation of these polymers, $1 \%$ wt of SPBPO was respectively used for TMPTA and Glyfoma based polymer pellets when the NIR dye range varied from $0 \%_{\mathrm{wt}}$ to $2 \%_{\mathrm{wt}}$. Finally, the concentration of the thickener used for thermoplastic samples was fixed to $1 \%$ wt.

Photopolymerization experiments enabling to access to thermosets or thermoplastics were carried out at room temperature upon irradiation with a laser diode at $405 \mathrm{~nm}$ (450 $\mathrm{mW} . \mathrm{cm}^{-2}$ ) in a mold. It should be noticed that the UV photoinitiator and the two NIR dyes have been selected so that no (or-low) overlap of their respective absorptions could exist, reducing the risk for the NIR dye to be involved in the polymerization process and to be degraded. A Jasco 6600 real-time Fourier transformed infrared spectroscopy (RT-FTIR) was used to monitor the $\mathrm{C}=\mathrm{C}$ acrylate double bond conversion between 6100 and $6200 \mathrm{~cm}^{-1}$ during the irradiation time. Polymer films with a thickness of $2 \mathrm{~mm}$ were prepared in these experiments.

\subsection{Heater effect followed by infrared thermal imaging camera}

In order to follow the heater effect of the NIR dyes in-situ embedded into thermoset or thermoplastic samples, different NIR light sources were used: i) laser diodes @785, 940, 980 and $1064 \mathrm{~nm}$ or ii) LED@850 nm. Excitations with the NIR light source were done at a distance of $2 \mathrm{~cm}$ for the laser diodes and $6 \mathrm{~cm}$ for the LEDs. The exposure time of samples varied from three minutes for the characterization of the photothermal effect to ten minutes for 
thermoplastic properties experiments. A Fluke TiX500 infrared thermal imaging camera was used to follow in real time the temperature reached by the polymer.

\subsection{UV-VIS Absorption spectroscopy}

A Jasco V-750 spectrophotometer was used to measure the UV-visible absorption spectra of both IR-813 and SQ in toluene and acetonitrile.

\subsection{Differential Scanning Calorimetry (DSC)}

The DSC Mettler Toledo DSC1 coupled to the Star software was used to determine the glass transition temperature under air of the thermoplastic samples. Tests were performed from $0^{\circ} \mathrm{C}$ to $200^{\circ} \mathrm{C}$ with a rise in temperature of $10 \mathrm{~K} \cdot \mathrm{min}^{-1}$. These latter were heated twice: a first run was carried out to erase their thermal backgrounds and a second run was performed in order to determine the $\mathrm{T}_{\mathrm{g}}$ by drawing the tangent of the transition phase.

\subsection{Thermogravimetric analysis (TGA)}

The Mettler Toledo TGA DSC 3+ and the Star software were used to measure the thermal decomposition temperature of the heaters under air. These latter were heated from $30^{\circ} \mathrm{C}$ to $900^{\circ} \mathrm{C}$ with a rise in temperature of $10 \mathrm{~K} \cdot \mathrm{min}^{-1}$.

\subsection{Optical microscopy}

The PX-8085-919 optical microscope (from Somikon) was used to follow the evolution of scratched thermoplastic samples over irradiation time. This optical microscope has a total magnification $200 \times$ which allows to record high quality pictures.

\section{Results and discussion}

Photopolymerizations of TMPTA-based photosensitive resins were recorded by RT-FTIR in order to follow the double bond of the acrylate function conversion in the presence of different heater contents. In order to determine the acrylate conversion, the relation $\left(1-\frac{A t}{A 0}\right) *$ 100 was used for each NIR dye concentrations with $A_{0}$ the initial area of the acrylate peak and $A_{t}$ the area of the acrylate peak at the time $t$ of the irradiation. An example of FTIR spectrum that was used to follow the acrylate $\mathrm{C}=\mathrm{C}$ double bond is given in Figure $\mathrm{S} 1$ in supporting 
information. The kinetics recorded for different concentrations of IR-813 are depicted in Figure 1 and those with SQ are given in supporting information (Figure S2 in supporting information).

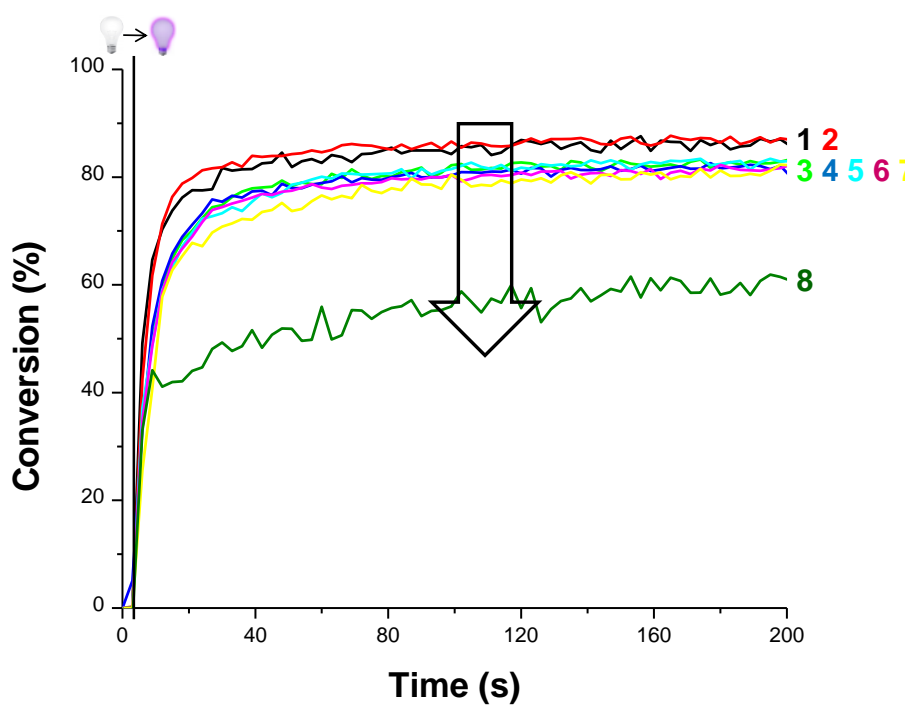

Figure 1. Photopolymerization profiles (acrylate $\mathrm{C}=\mathrm{C}$ function conversion versus irradiation time) for TMPTA samples in the presence of SPBPO (1\% wt) and IR-813 at (1) $0 \%_{\mathrm{wt}}$, (2) $0.01 \%_{\mathrm{wt}}$, (3) $0.02 \%_{\mathrm{wt}}$, (4) $0.04 \%$ wt, (5) $0.05 \%$ wt, (6) $0.08 \%$ wt, (7) $0.1 \%$ wt and (8) $0.2 \% \%_{\mathrm{wt}}$; $2 \mathrm{~mm}$ thick samples ; in laminate ; irradiation with a laser diode at $405 \mathrm{~nm}\left(\mathrm{t}=0 \mathrm{~s}, 450 \mathrm{~mW} \cdot \mathrm{cm}^{-2}\right)$. Irradiation beginning at $\mathrm{t}=4 \mathrm{~s}$.

As shown above, the final acrylate function conversion is unaffected when the IR- 813 concentration is under $0.1 \% \mathrm{wt}$ but a decrease in the final monomer conversion is observed for higher concentration. This phenomenon can be ascribed to a light absorption by the dye @ $405 \mathrm{~nm}$ in competition with that of the photoinitiator (SPBPO) as its concentration increases. For SQ, a similar behavior was observed; the polymerization profiles were not affected for a NIR dye content lower than $0.08 \%$ wt but poorer profiles are observed for higher contents due to internal filter effect. The molar extinction coefficients of IR-813 and SQ have been evaluated from their UV-Visible absorption spectra using the Beer-Lambert law and the values are reported in the Table 1.

Table 1. Molar extinction coefficients of IR-813 and SQ in toluene calculated from their UV-visible absorption spectra using the Beer-Lambert law $\mathrm{A}=\varepsilon 1 \mathrm{c}$ at $405 \mathrm{~nm}$.

\begin{tabular}{|l|l|l|}
\hline & IR-813 & SQ \\
\hline
\end{tabular}




\begin{tabular}{|l|l|c|}
\hline$\varepsilon\left(\mathrm{L}^{\mathrm{mol}}{ }^{-1} \cdot \mathrm{cm}^{-1}\right)$ & 5600 & 3800 \\
& & \\
\hline
\end{tabular}

In this first part, we showed that it was possible to in-situ embed a NIR heater into a polymer film by photopolymerizing the TMPTA monomer with a UV-visible photoinitiator (SPBPO) upon excitation at $405 \mathrm{~nm}$. Since the NIR heater was not involved in the photopolymerization process, its chemical integrity was maintained. In a second step, NIR heaters can be used to activate the photothermal effect by irradiation with a NIR light. Indeed, heaters will release heat by absorbing the NIR light. Various parameters influencing the maximum temperature reached by the polymer films were investigated, namely the irradiance (see Figure 2), the choice of the heater (SQ vs. IR-813), the heater weight content or the NIR irradiation wavelength. Figure 2 clearly shows a huge increase of the polymer temperature in the presence of IR-813 and irradiation of the polymer films with a NIR light. It is possible to control the temperature reached by the polymer by controlling the irradiance i.e. a higher irradiance leading to a higher temperature. The same behavior was demonstrated with SQ as a second NIR dye (see Figure S3 in SI). For both NIR heaters, the maximal temperatures reached by the polymer films $v s$. the irradiance followed a linear plot; this can be highly useful to control the processing of the polymer when a given temperature is desired for shaping, bonding/debonding, self-healing or recycling processes. For the different polymers prepared in the same conditions but not containing a NIR heater, only a very slight increase of the internal temperature was observed and the final value reached never exceeded $40^{\circ} \mathrm{C}$ contrary to more than $150^{\circ} \mathrm{C}$ in the presence of the NIR heaters. This clearly shows that the presence of the NIR heaters and the use of a NIR light were both required to drastically increase the temperature of the polymer films and thus the easiness for (re)processing the polymer films. 


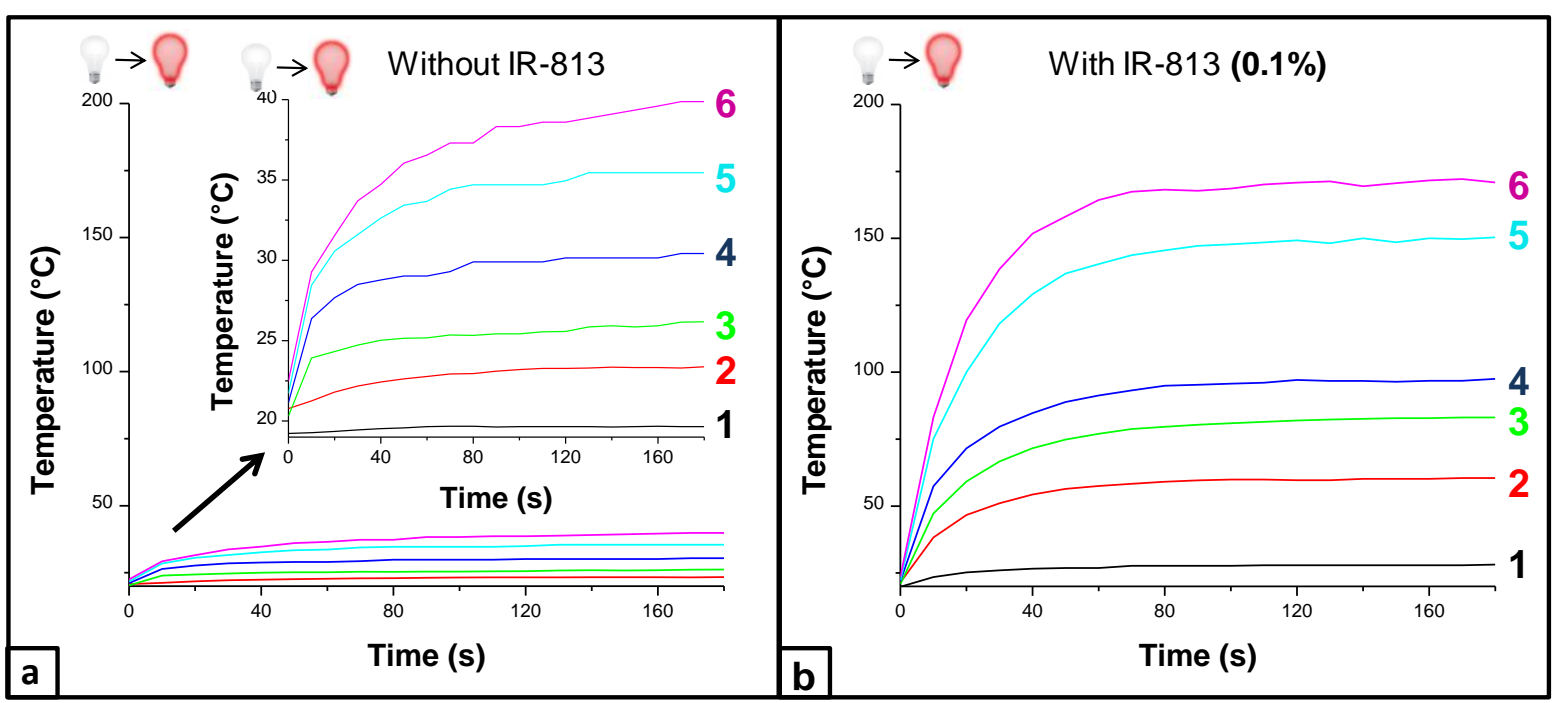

Figure 2. (a) Temperature versus NIR irradiation time for TMPTA-based polymers under different irradiances of a NIR light source at $785 \mathrm{~nm}$ without additional NIR heater. (b) Temperature versus NIR irradiation time for TMPTA-based polymers under different irradiances of NIR irradiation at 785 $\mathrm{nm}$ and in the presence of IR-813 $\left(0.1 \%_{\mathrm{wt}}\right)$. (1) $\mathrm{I}=0.4 \mathrm{~W} \cdot \mathrm{cm}^{-2}$; (2) $\mathrm{I}=0.8 \mathrm{~W} \cdot \mathrm{cm}^{-2}$; (3) I $=1.2 \mathrm{~W} . \mathrm{cm}^{-2}$; (4) $\mathrm{I}=1.6 \mathrm{~W} \cdot \mathrm{cm}^{-2} ;(5) \mathrm{I}=2.4 \mathrm{~W} \cdot \mathrm{cm}^{-2} ;(6) \mathrm{I}=2.55 \mathrm{~W} \cdot \mathrm{cm}^{-2}$. The irradiation starts from $\mathrm{t}=0 \mathrm{~s}$.

Another factor influencing the maximal temperature reached by the polymer film is the selected NIR wavelength. Indeed, the two NIR dyes can absorb differently in the NIR range and preferential wavelengths can be thus selected to improve the light-to-heat conversion. To illustrate this, by absorbing more light, the NIR dye can thus produce more heat. Therefore, it is of crucial interest to get a perfect matching between the emission wavelength of the NIR light used to excite the NIR heaters and their respective absorptions. Table 2 and Figure S4 in supporting information summarize the different temperatures reached by the polymer films at different irradiation wavelengths, for the reference system (without heater) and the systems comprising a NIR heater. The presence of a NIR heater is clearly mandatory i.e. without NIR heater, a very low photothermal effect is found $\left(\mathrm{T}<40^{\circ} \mathrm{C}\right.$, Table 2$)$. Two trends can be clearly established from these results; notably that IR-813 is more adapted for irradiations with shorter NIR wavelengths (approximately under $850 \mathrm{~nm}$ ) i.e. at $785 \mathrm{~nm}$, a temperature as high as $170^{\circ} \mathrm{C}$ could be reached. Conversely, the system comprising SQ is more adapted for irradiation with longer NIR wavelengths (approximately over $850 \mathrm{~nm}$ ) e.g. a temperature above $256^{\circ} \mathrm{C}$ could be reached for the SQ-based systems upon excitation at $1064 \mathrm{~nm}$ whereas the temperature only reached $38^{\circ} \mathrm{C}$ for the IR-813-based system. These results are in perfect agreement with the NIR light absorption properties of the two dyes as it is shown in the Figure 3. 
Table 2. Maximal temperatures reached for the TMPTA-based polymers in the presence of heaters $(0.05 \%$ wt $)$ upon irradiation at different NIR wavelengths. The irradiance was $2.55 \mathrm{~W} . \mathrm{cm}^{-2}$ at $785 \mathrm{~nm}, 1$ W.cm ${ }^{-2}$ at $850 \mathrm{~nm}, 2.16 \mathrm{~W} . \mathrm{cm}^{-2}$ at $940 \mathrm{~nm}, 3.12 \mathrm{~W} . \mathrm{cm}^{-2}$ at $980 \mathrm{~nm}$ and $3.12 \mathrm{~W} . \mathrm{cm}^{-2}$ at $1064 \mathrm{~nm}$.

\begin{tabular}{|c|c|c|c|}
\hline & Without heater & Heater IR-813 & Heater SQ \\
\hline $785 \mathrm{~nm}$ & $40^{\circ} \mathrm{C}$ & $171^{\circ} \mathrm{C}$ & $143^{\circ} \mathrm{C}$ \\
\hline $850 \mathrm{~nm}$ & $38^{\circ} \mathrm{C}$ & $87^{\circ} \mathrm{C}$ & $97^{\circ} \mathrm{C}$ \\
\hline $940 \mathrm{~nm}$ & $28^{\circ} \mathrm{C}$ & $54^{\circ} \mathrm{C}$ & $174^{\circ} \mathrm{C}$ \\
\hline $980 \mathrm{~nm}$ & $27^{\circ} \mathrm{C}$ & $59^{\circ} \mathrm{C}$ & $260^{\circ} \mathrm{C}$ \\
\hline $1064 \mathrm{~nm}$ & $32^{\circ} \mathrm{C}$ & $38^{\circ} \mathrm{C}$ & $256^{\circ} \mathrm{C}$ \\
\hline
\end{tabular}

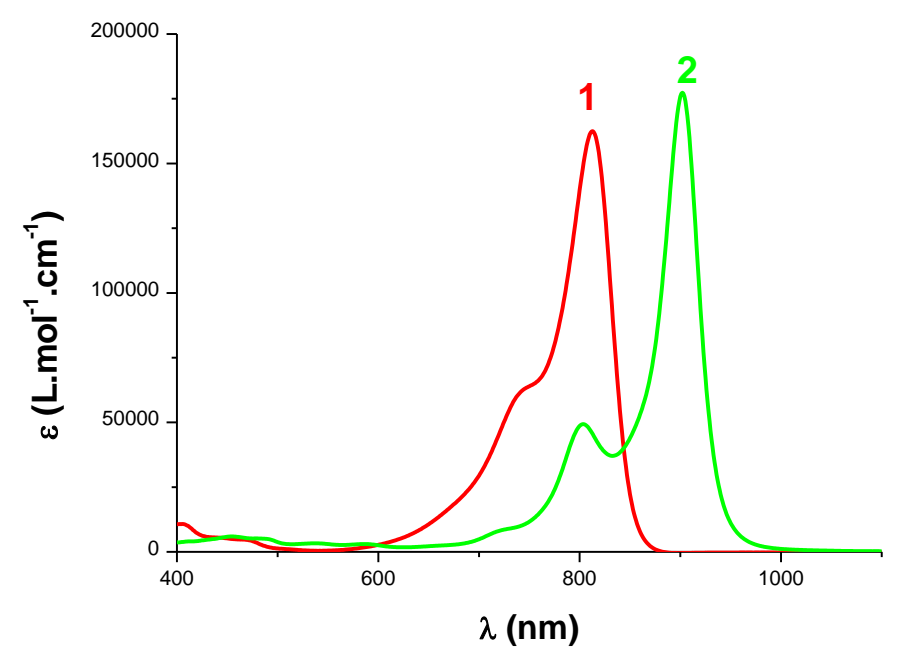

Figure 3. Molar extinction coefficients of (1) IR-813 in acetonitrile and (2) SQ in toluene.

Another parameter governing the temperature reached by the polymer films is the heater concentration. As shown in the Figure 4, only a very low content of heater is necessary to reach an efficient photothermal effect (Figure $4 \mathrm{a} ;<0.05-0.1 \% \mathrm{w} / \mathrm{w}$ ). A linear correlation can be established for the two dyes by plotting the temperature $v s$. the heater's weight content when a logarithmic scale is used for the abscissa (Figure 4b). These heaters could potentially be used for the reprocessing or the reactivation of the thermoplastics on request as high temperatures can be reached even for very low heater contents $\left(<0.1 \%_{\mathrm{wt}}\right)$. It is shown in supporting information that IR-813 is not decomposed before $250^{\circ} \mathrm{C}$ (Figure S5) and that SQ is still on a 
good shape until $400^{\circ} \mathrm{C}$ (Figure S6). Considering that $\mathrm{T}_{\mathrm{g}}$ of important classes of thermoplastics are below $150^{\circ} \mathrm{C}$, the proposed approach is probably already very powerful and adapted for most of the thermoplastics.

Clearly, the organic NIR dyes should be privileged as heaters. Indeed, organic dyes exhibit a better photothermal effect and are easier to use than inorganic structures such as fillers (no precipitation and good solubility).[20] In fact, photothermal effect produced by NIR dye can greatly outperform that of the nanoparticles.[13][15] Indeed, a previous study reported that only a temperature of $90^{\circ} \mathrm{C}$ was reached with $1 \%$ wt of polydopamine@ polypyrrole nanoparticle under 2 W. $\mathrm{cm}^{-2}$ of NIR light $(808 \mathrm{~nm})$. In the same way, NIR dyes are outperforming inorganic fillers.[18][19] Indeed, composites using $0.5 \%$ wt graphene oxide as heater do not reach high temperatures $\left(100^{\circ} \mathrm{C}\right)$ under more than $2 \mathrm{~W} . \mathrm{cm}^{-2}$ of NIR light. However, the same temperature could be reached for a much lower concentration of IR-813 NIR dye and under a lower irradiance of NIR light $(785 \mathrm{~nm})$ than that used in the case of fillers.

In a second step, the two NIR heaters examined in this work have been used in combination with thermoplastics.

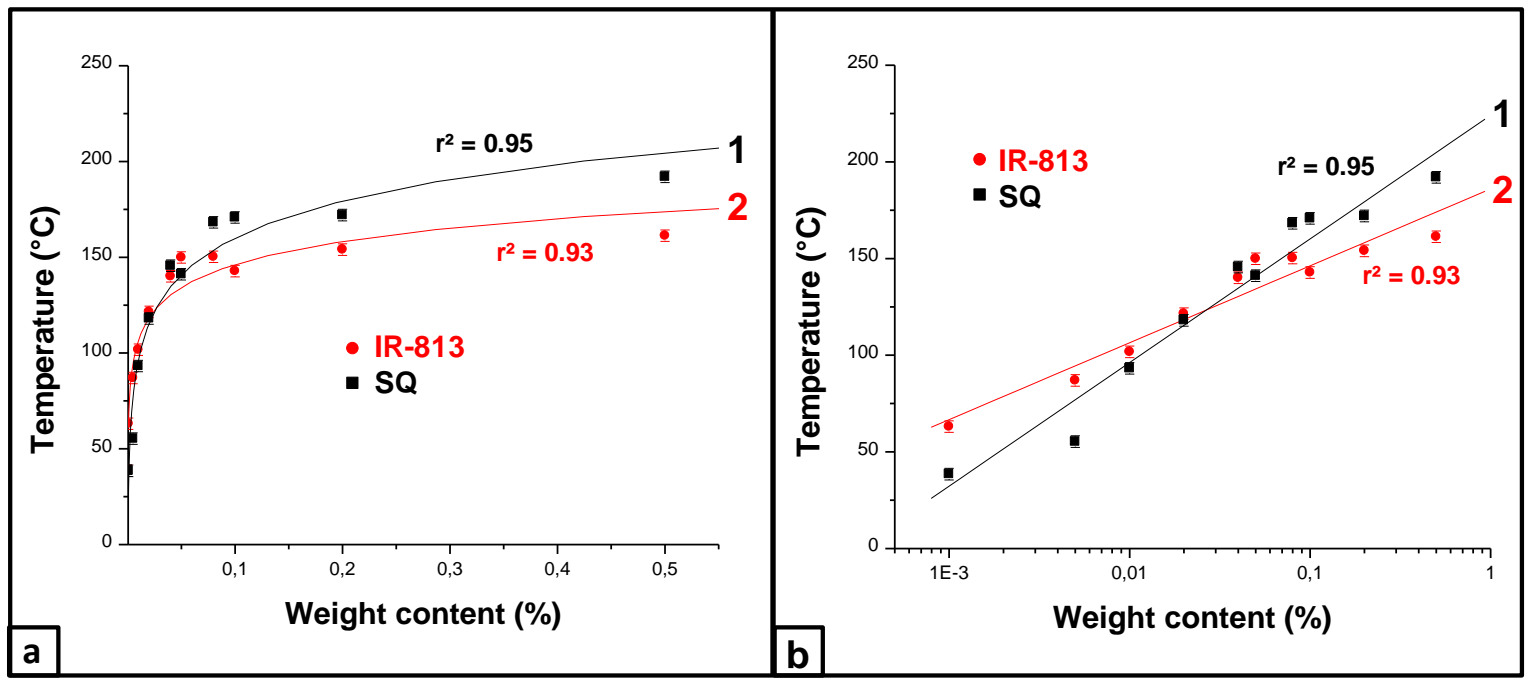

Figure 4. Maximal temperatures reached by the TMPTA-based polymers for various heater concentrations under NIR irradiation at $785 \mathrm{~nm}\left(2.55 \mathrm{~W} . \mathrm{cm}^{-2}\right)$ on a (a) linear scale and on a (b) logarithmic scale for systems with (1) SQ and (2) IR-813. 
Some tests have been performed on a thermoplastic material based on Glyfoma in order to reprocess it i.e. self-healing and bonding/debonding applications were first investigated to show the interest of the approach. As shown above for TMPTA, photopolymerization of Glyfoma in the presence of SPBPO is not (or weakly) affected by the presence of IR-813 when its content is under $0.1 \%_{\text {wt }}$ (Figure S7). Furthermore, presence of NIR heaters in the synthesized polymers allows their activation with a NIR light e.g. a temperature as high as $190^{\circ} \mathrm{C}$ can be reached by irradiation at $785 \mathrm{~nm}\left(2 \mathrm{~W} . \mathrm{cm}^{-2}\right)$ in the presence of IR-813 (Figure S8).

To characterize the thermoplastics obtained, DSC measurements have been carried out on the reference system (without heater) and on systems with the NIR heater in-situ embedded after a first photopolymerization step done at $405 \mathrm{~nm}$. The glass transition temperatures of the prepared glyfoma-based polymers are around $70-80^{\circ} \mathrm{C}$ (see Figures S9-S11 in SI).

As explained in the Scheme 3, a possible bonding strategy between two thermoplastics could consist in incorporating the NIR heater in each of them and irradiating them with a NIR light. Increase of the temperature above the $\mathrm{T}_{\mathrm{g}}$ upon excitation with a NIR light will enable the interpenetration of the polymer chains of the two polymer films, leading to a strong bonding of the two materials.

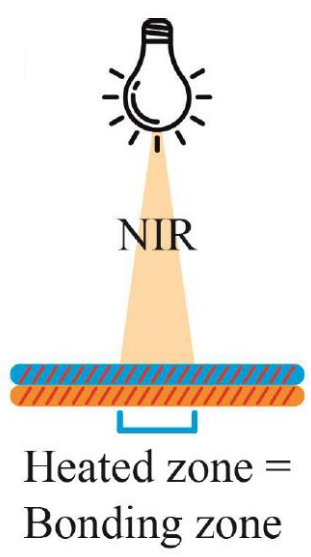

Scheme 3. Bonding of two polymer films containing a NIR heater in each film.

Therefore, to bond two thermoplastics together, a simple experiment has been designed: two polymers were hold together and irradiated from the top side. As shown in the Figure 5a, thermoplastics free of heaters could not be bonded even after 3 hours of irradiation with a NIR light as the temperature reached by the polymers (not even $45^{\circ} \mathrm{C}$ ) was lower than its $\mathrm{T}_{\mathrm{g}}$. 
However, thermoplastics containing heaters could be bonded together very efficiently after only 10 minutes of NIR light irradiation with SQ (Figure 5b) as the temperature reached by the polymers was high enough (almost $100^{\circ} \mathrm{C}$ ), overcoming the $\mathrm{T}_{\mathrm{g}}$. For IR-813, the thermoplastics could be bonded together even more rapidly, within 5 minutes (Figure $5 \mathrm{c}$ ) in agreement with a higher photothermal effect (more than $150^{\circ} \mathrm{C}$ ) with IR-813@785 nm. For wavelengths $>850$ $\mathrm{nm}$, faster bonding can be obtained with SQ than with IR-813, what can be easily explained by its red-shifted absorption compared to that of IR-813 (See Figure 3). Due to the better adequation of its absorption spectra for long wavelength, temperature $>150^{\circ} \mathrm{C}$ could be obtained with SQ upon irradiation at $980 \mathrm{~nm}$ of Glyfoma-based thermoplastic polymers (See Figure S12 in SI). It is crucial to mention that the bonding is totally reversible, the separation of the $t$ wo thermoplastic polymers being possible by re-irradiating the polymers with a NIR light.

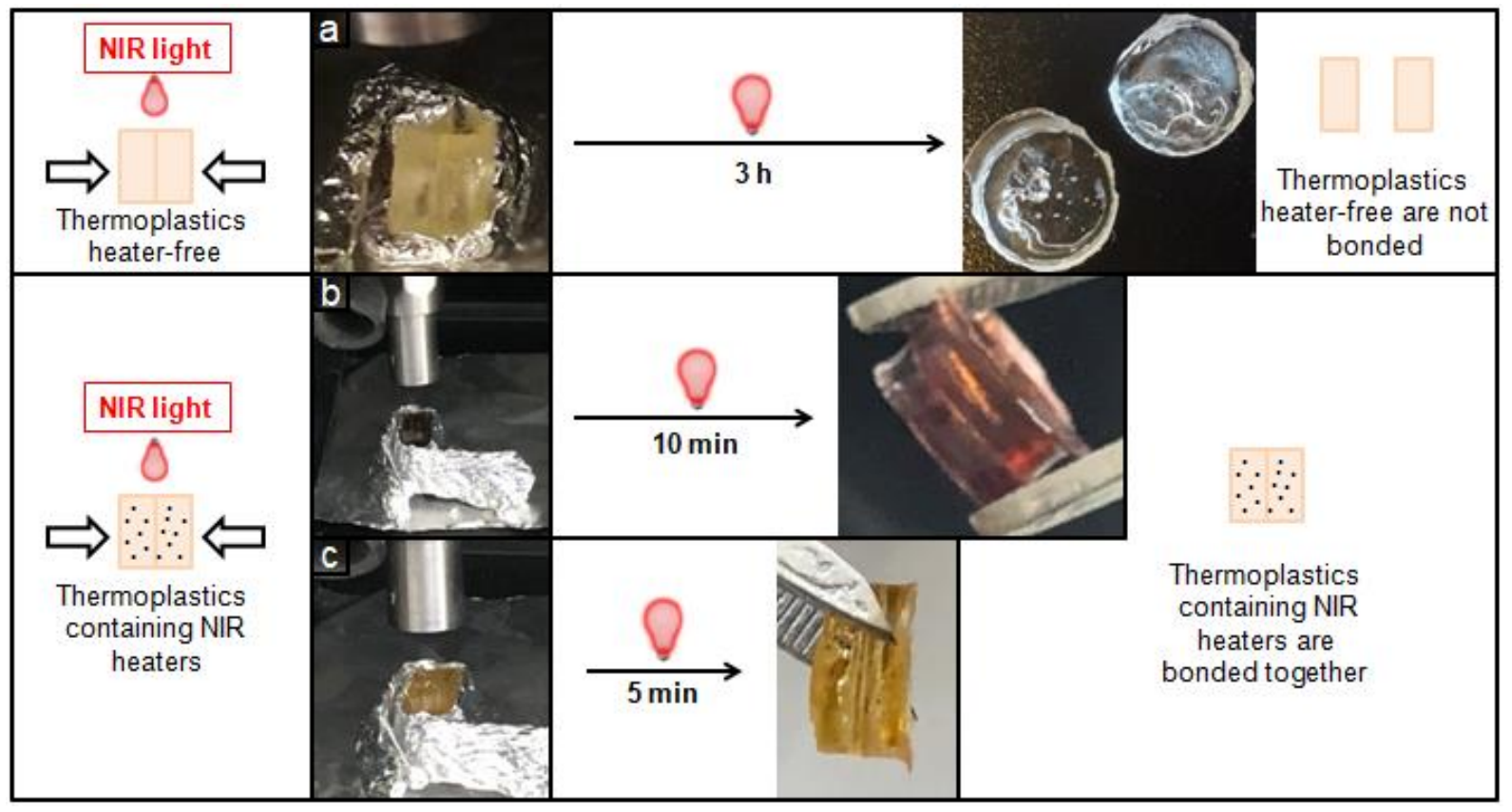

Figure 5. Photos before (left) and after NIR irradiation (right) of two Glyfoma-based thermoplastic polymers put in contact and irradiated from the top: (a) without heater (no bonding of the two polymer pellets), (b) with $0.05 \%$ wt of SQ and (c) with $0.05 \%$ wt of IR-813 upon NIR light irradiation at $785 \mathrm{~nm}$ and $2.55 \mathrm{~W} \cdot \mathrm{cm}^{-2}$. The two polymers cannot be separated for $\mathbf{b}$ ) and $\mathbf{c}$ ).

As already mentioned, the advantage of using laser diodes instead of ovens to increase the polymer temperature higher than its glass transition temperature relies in the possibility to perfectly control the position of the heated area and thus to get a spatial control. Indeed, the 
Figure 6A shows a NIR irradiation of around $4 \mathrm{~mm}$ diameter but depending on the diameter of the optical fibre, the scale of the spatial control can be even better using lasers. On the opposite, in ovens, the whole material is heated so that no spatial control is possible. In the case of a thermoplastic, control of the heated zone allows to get a remarkable precision on its shape modification as shown in Figure 6B for the shaping of a thermoplastic. An example of shaping for a Glyfoma-based thermoplastic containing IR-813 (0.1\% wt) as heater is provided in Figure 6C i.e. upon NIR LED@850 nm irradiation $\left(1 \mathrm{~W} \mathrm{~cm}^{-2}\right)$, the molding of the thermoplastic is possible.

(A)

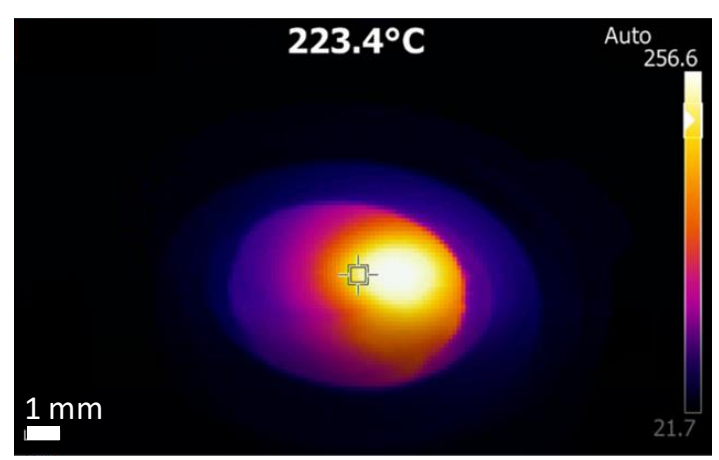

(B)

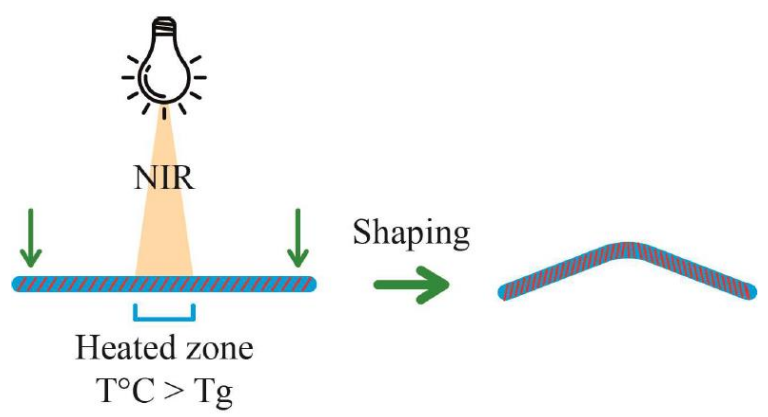

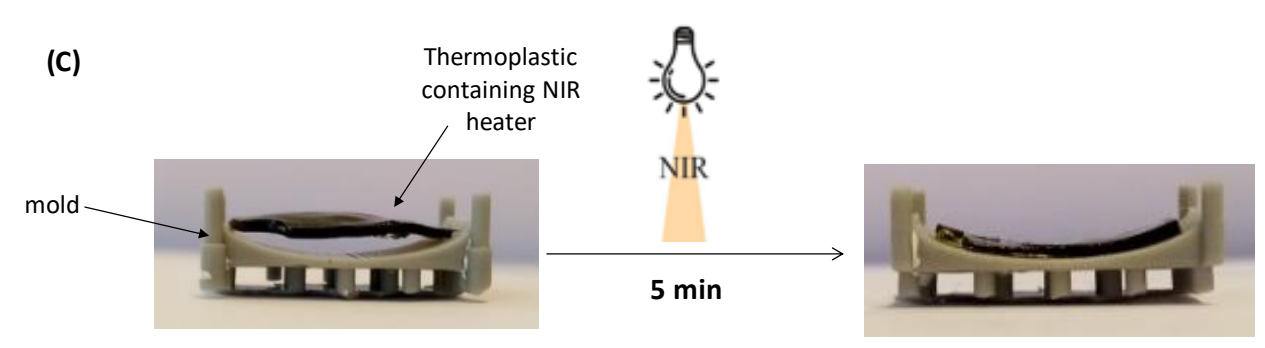

Figure 6. (A) spatial control of the temperature observed during irradiation of a Glyfoma-based thermoplastic polymer with a NIR light and observed by thermal imaging experiments; (B) principle of this spatial control for the shaping of a thermoplastic in its central part under NIR irradiation; (C) example of shaping upon NIR light for a Glyfoma-based thermoplastic with IR-813 (0.1\% wt) as heater upon LED@850 nm $\left(1 \mathrm{~W} \mathrm{~cm}^{-2}\right)$.

Some self-healing experiments have also been carried out in order to characterize the ability of the polymer films to recover their initial shape by chain mobility above the $\mathrm{T}_{\mathrm{g}}$. In this aim, scratches of around $100 \mu \mathrm{m}$ depth and $500 \mu \mathrm{m}$ width has been made and could be very efficiently healed just by irradiating the surface with a NIR light. As shown in the Figure 7A, after only 10 minutes of NIR irradiation at $785 \mathrm{~nm}\left(2.55 \mathrm{~W} . \mathrm{cm}^{-2}\right)$, the scratches were already 
healed. Evolution of a scratch upon NIR irradiation at $785 \mathrm{~nm}$ is given in the Figure 7B. This self-healing ability is possible as the temperature reached by the thermoplastic was higher than its $\mathrm{T}_{\mathrm{g}}$ (more than $100^{\circ} \mathrm{C}$ above the $\mathrm{T}_{\mathrm{g}}$ in this case). These results bode good future for thermoplastics self-healing, shaping and/or reprocessing upon NIR light. Another example of photothermal effect in methyl methacrylate (MMA) based thermoplastic is given in Figure S13 to highlight the versatility of the proposed approach.

A

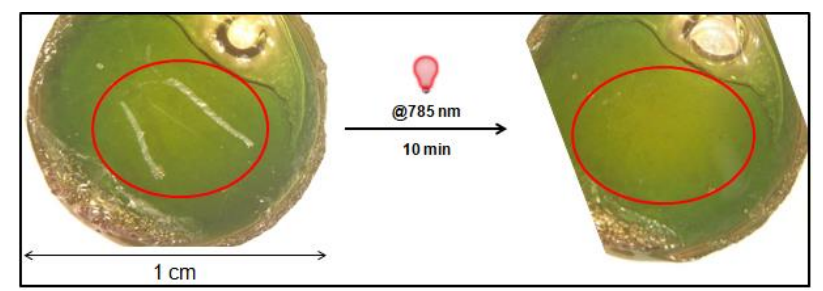

B

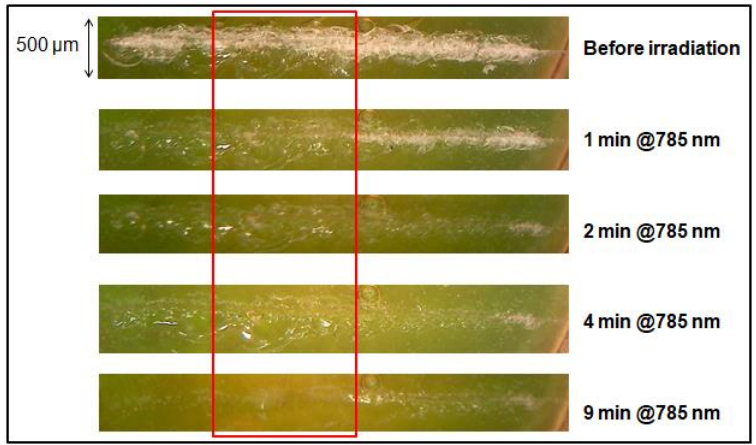

Figure 7. Self-healing of a scratched Glyfoma-based thermoplastic with $0.1 \%_{\text {wt }}$ of IR-813 upon NIR light irradiation at $785 \mathrm{~nm}$ and 2.55 W. $\mathrm{cm}^{-2}$.

\section{Conclusion}

In conclusion, internal temperature of different polymers (thermosets or thermoplastics) could be finely tuned by using low NIR heater content $(<0.1 \% \mathrm{w} / \mathrm{w})$. By mean of a careful selection of the NIR dye structure, the concentration but also the excitation wavelength and the irradiance, for the first time, the heat released inside the polymer matrix could be precisely controlled (from the light intensity and heater concentration; Figure $2 \& 4$ ) leading to unprecedented activation possibilities of thermoplastics. The good thermal stability of SQ and IR-813 coupled with the low glass transition temperature of the thermoplastics used in this work allowed a large flexibility in the operating temperature for reprocessing. Notably, to evidence the pertinence of the strategy, two selected examples were given through bonding/debonding and self-healing applications. IR-813 was found to be more effective upon irradiation at short NIR wavelengths $(785-850 \mathrm{~nm})$ whereas SQ was more effective at longer NIR wavelengths $(850-1064 \mathrm{~nm})$. The use of this fully controlled photothermal effect induced by well-selected 
NIR organic heaters will be investigated for the recycling and the reshaping of other plastics (e.g. thermoplastics of different $\mathrm{T}_{\mathrm{g}}$ ) in forthcoming papers. 


\section{$\underline{\text { References }}$}

[1] Devezas, T.C. ; Vaz, A.M. ; Magee, C.L. Global Pattern in Material Consumption: An Empirical Study. In: Industry 4.0 2017, Springer, Cham, 263-29 2.

[2] Plastics : the Facts 2007. www.plasticseurope.org, accessed date: 04 February 2020.

[3] Plastics : the Facts 2018. www.plasticseurope.org, accessed date: 04 February 2020.

[4] Maris, J. ; Bourdon, S. ; Brossard, J-M. ; Cauret, L. ; Fontaine, L. ; Montembault, V. Mechanical Recycling: Comptabilisation of Mixed Thermoplastic Wastes. Polymer Degradation and Stability 2018, 147, 245-266.

[5] Huysman, S. ; Debaveye, S. ; Schaubroeck, T. ; De Meester, S. ; Ardente, F. ; Mathieux, F. ; Dewulf, J. The Recyclability Benefit Rate of Closed-Loop and Open-Loop Systems: A Case Study on Plastic Recycling in Flanders. Ressources, Conservation and Recycling 2015, 202, 53-60.

[6] Gradus, R. ; Nillesen, P. ; Dijkgraaf, E. ; van Koppen, R. A Cost-effectiveness Analysis for Incineration or Recycling of Dutch Household Plastic Waste. Ecological Economics 2017, 135, $22-28$.

[7] Gawande, A. ; Zamare, G. ; Renge, V.C. ; Tayde, S. ; Bharsakale, G. An Overview On Waste Plastic Utilization in Asphalting of Roads. Journal of Engineering Research and Studies 2012, 3 (2), 01-05.

[8] Li, K. ; Xu, Z. ; Zhao, S. ; Meng, X. ; Zhang, R. ; Li, J. ; Leng, J. ; Zhang, G. ; Cao, D. ; Sun, R. Biomimetic, recyclable, highly stretchable and self-healing conductors enabled by dual reversible bonds. Chemical Engineering Journal 2019, 371, 203-212.

[9] Zhang, Y. ; Yin, X-Y. ; Zheng, M. ; Moorlag, C. ; Yang, J. ; Wang, Z.L. 3D printing of thermoreversible polyurethanes with targeted shape memory and precise in situ self-healing properties. Journal of Materials Chemistry A 2019, 7, 6972.

[10] Feng, L. ; Yu, Z. ; Bian, Y.; Lu, J. ; Shi, X. ; Chi, C. Self-healing behaviour of polyurethanes based on dual actions of thermo-reversible Diels-Alder reaction and thermal movement of molecular chains. Polymer 2017, 124, 48-59.

[11] Luo, X. ; Mather, P.T. Shape Memory Assisted Self-Healing Coating. ACS Macro Lett. 2013, 2(2), 152-156.

[12] Kong, D. ; Li, J. ; Guo, A. ; Zhang, X. ; Xiao, X. Self-healing high temperature shape memory polymer. European Polymer Journal 2019, 120, 109279.

[13] Dong, Y. ; Gong, M. ; Huang, D. ; Gao, J. ; Zhou, Q. Shape memory, self-healing property, and NIR photothermal effect of epoxy resin coating with polydopamine@polypyrrole nanoparticles. Progress in Organic Coatings 2019, 136, 105232. 
[14] Bai, Y. ; Zhang, J. ; Wen, D. ; Gong, P. ; Liu, J. ; Ju, J. ; Chen, X. A reconfigurable, selfhealing and near-infrared light responsive thermoset shape memory polymer. Composite Science and Technology 2020, 187, 107940.

[15] Yang, S. ; Du, X. ; Du, Z.; Zhou, M. ; Wang, H. ; Yan, B. Robust, stretchable and photothermal self-healing polyurethane elastomer based on furan-modified polydopamine nanoparticles. Polymer 2020, 190, 122219.

[16] Peng, P. ; Zhang, B. ; Cao, Z. ; Hao, L. ; Yang, F. ; Jiao, W. ; Liu, W. ; Wang, R. Photothermally induced scratch healing effects of thermoplastic nanocomposites with gold nanoparticles. Composites Science and Technology 2016, 133, 165-172.

[17] Zare, Y. Study of nanoparticles aggregation/agglomeration in polymer particulate nanocomposites by mechanical properties. Composites: Part A 2016, 84, 158-164.

[18] Punetha, V.D. ; Ha, Ha, Y-M. ; Kim Y-O. ; Jung, Y.C. ; Cho, J.W. Rapid remote actuation in shape memory hyperbranched polyurethane composites using cross-linked photothermal reduced graphene oxide networks. Sensors and Actuators B: Chemical 2020, 321, 128468.

[19] Punetha, V.D. ; Ha, Ha, Y-M. ; Kim Y-O. ; Jung, Y.C. ; Cho, J.W. Interaction of photothermal graphene networks with polymer chains and laser-driven photo-actuation behavior of shape memory polyurethane/epoxy/epoxy-functionalized graphene oxide nanocomposites. Polymer 2019, 181121791.

[20] Bonardi, A-H. ; Bonardi, F. ; Dumur, F. ; Gigmes, D. ; Fouassier, J-P. ; Lalevée, J. Fillers as Heaters for Photothermal Polymerization upon NIR Light. Macromolecular Rapid Communications 2019, 40 (23).

[21] Bonardi, A-H. ; Dumur, F. ; Grant, T.M. ; Noirbent, G. ; Lessard, B.H. ; Fouassier, J-P. ; Lalevée, J. High Performance Near-Infrared (NIR) Photoinitiating Systems Operating under Low Light Intensity and in the Presence of Oxygen. Macromolecules 2018, 51 (4), 1314-1324.

[22] Pan, Y. ; Fan, S. ; Wang, Q. ; Oprych, D. ; Feilen, A. ; Reiner, K. ; Keil, D. ; Slominsky, Y.L. ; Popov, S. ; Zou, Y.; Strehmel, B. NIR-Sensitized Activated Photoreaction between Cyanines and Oxime Esters: Free-Radical Photopolymerization. Angewandte Chemie International Edition 2020, 59, 11440-11447.

[23] Yuan, A. ; Wu, J. ; Tang, X. ; Zhao, L. ; Xu, F. ; Hu, Y. Application of Near-Infrared Dyes for Tumor Imaging Photothermal, and Photodynamic Therapies. Journal of Pharmaceutical Sciences 2013, 102 (1), 06-28.

[24] Jiyang, Y. ; Duan, X. ; Bai, J. ; Tian, H. ; Ding, D. ; Geng, Y. Polymerization-induced photothermy: A non-donor-acceptor approach to highly effective near-infrared photothermal conversion nanoparticles. Biomaterials 2020, 255, 120179.

[25] Zhang, X. ; Si, Z. ; Wang, Y. ; Li, Y. ; Xu, C. ; Tian, H. Polymerization and coordination synergistically constructed photothermal agents for macrophages-mediated tumor targetinf diagnosis and therapy. Biomaterials 2021, 264, 120382. 
[26] Schmitz, C. ; Halbhuber, A. ; Keil, D. ; Strehmel, B. NIR-Sensitized Photoinitiated Radical Polymerization and Proton Generation with Cyanines and LED Arrays. Progress in Organic Coatings 2016, 100, 32-46.

[27] Bonardi, A-H. ; Bonardi, F. ; Morley-Savary, F. ; Dietlin, C. ; Noirbent, G. ; Grant, T.M., Fouassier, J-P. ; Dumur, F. ; Lessard, B.H. ; Gigmes, D. ; Lalevée, J. Photoinduced Thermal Polymerization Reactions. Macromolecules 2018, 51 (21), 8808-8820.

[28] Strassel, K. ; Kaiser, A. ; Jenatsch, S. ; Véron, A.C. ; Anantharaman, S.B. ; Hack, E. ; Diethelm, M. ; Nüesch, F. ; Aderne, R. ; Legnani, C. ; Yakunin, S. ; Cremona, M. ; Hany, R. Squaraine Dye for a Visibly Transparent All-Organic Optical Upconversion Device with Sensivity at $1000 \mathrm{~nm}$. ACS Applied Materials \& Interfaces 2018, 10, 11063-11069. 
TOC graphic :

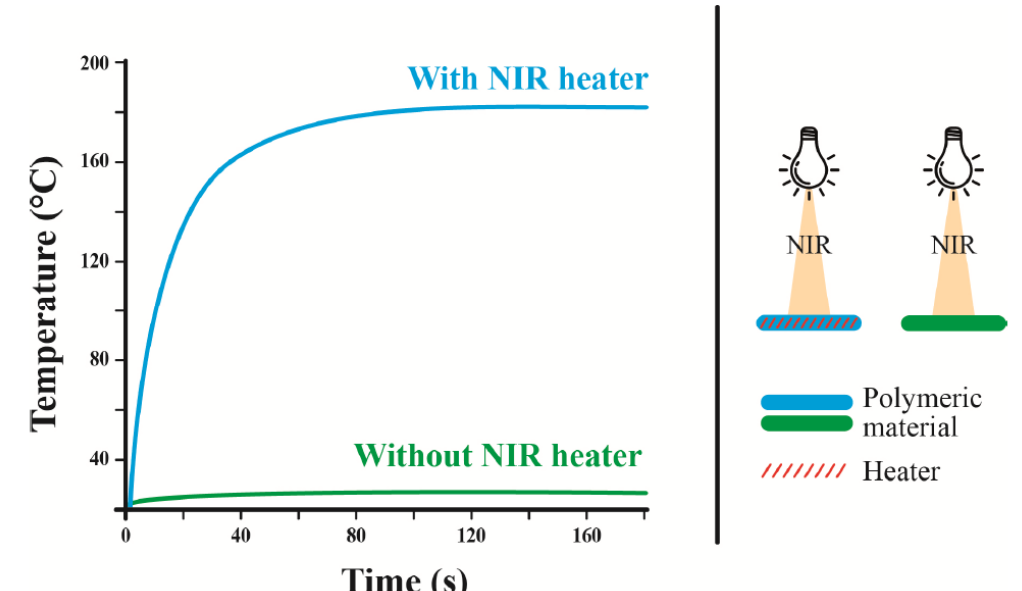

Time (s) 